\title{
Primary Cilia and Signaling Pathways in Mammalian Development, Health and Disease
}

\author{
Iben R. Veland ${ }^{\mathrm{a}}$ Aashir Awan $^{\mathrm{a}}$ Lotte B. Pedersen ${ }^{\mathrm{a}}$ Bradley K. Yoder $^{\mathrm{b}}$ \\ Søren T. Christensen ${ }^{a}$ \\ ${ }^{a}$ Department of Biology, Section of Cell and Developmental Biology, University of Copenhagen, Copenhagen, Denmark; \\ ${ }^{b}$ Department of Cell Biology, University of Alabama at Birmingham Medical School, Birmingham, Ala., USA
}

\section{Key Words}

Primary cilia · Cellular GPS · Signal transduction •

Development $\cdot$ Tissue homeostasis $\cdot$ Ciliopathies

\begin{abstract}
Although first described as early as 1898 and long considered a vestigial organelle of little functional importance, the primary cilium has become one of the hottest research topics in modern cell biology and physiology. Primary cilia are nonmotile sensory organelles present in a single copy on the surface of most growth-arrested or differentiated mammalian cells, and defects in their assembly or function are tightly coupled to many developmental defects, diseases and disorders. In normal tissues, the primary cilium coordinates a series of signal transduction pathways, including Hedgehog, Wnt, PDGFR $\alpha$ and integrin signaling. In the kidney, the primary cilium may function as a mechano-, chemo- and osmosensing unit that probes the extracellular environment and transmits signals to the cell via, e.g., polycystins, which depend on ciliary localization for appropriate function. Indeed, hypomorphic mutations in the mouse ift88 (previously called Tg737) gene, which encodes a ciliogenic intraflagellar transport protein, result in malformation of primary cilia, and in the collecting ducts of kidney tubules this is accompanied by development of autosomal recessive polycystic kidney disease (PKD). While PKD was one of the first diseases to be
\end{abstract}

linked to dysfunctional primary cilia, defects in this organelle have subsequently been associated with many other phenotypes, including cancer, obesity, diabetes as well as a number of developmental defects. Collectively, these disorders of the cilium are now referred to as the ciliopathies. In this review, we provide a brief overview of the structure and function of primary cilia and some of their roles in coordinating signal transduction pathways in mammalian development, health and disease.

Copyright $\odot 2009$ S. Karger AG, Basel

\section{Structure and Diversity of Cilia}

Cilia and flagella (the terms are equivalent) are antenna-like organelles that emanate from the surface of many growth-arrested or differentiated eukaryotic cells. They consist of a microtubule (MT)-based axoneme ensheathed by a bilayer lipid membrane that is continuous with the plasma membrane of the cell body, but contains a distinct subset of receptors and other proteins involved

This review is based on an invited lecture given during the Takis Anagnostopoulos Symposium on Renal and Epithelial Physiology and Physiopathology at Faculté de Médecine Necker in Paris, June 26-27, 2008.

\section{KARGER}

(c) 2009 S. Karger AG, Basel

Fax +41613061234 E-Mail karger@karger.ch www.karger.com www.karger.com/nep
Dr. Søren Tvorup Christensen

Department of Biology, Section of Cell and Developmental Biology

The August Krogh Building, Universitetsparken 13, University of Copenhagen

DK-2100 Copenhagen OE (Denmark)

Tel. +45 353217 05, Fax +45353215 67, E-Mail stchristensen@bio.ku.dk 
in signaling. The axoneme grows out from the distal end of a modified centriole, the basal body, which provides a template for the formation of the 9-fold symmetry of the ciliary axoneme, and also serves to anchor the axoneme in the cell. Separating the ciliary and plasma membrane compartments is a region known as the ciliary necklace [1]. The ciliary necklace is connected via fibers to the transition zone of the basal body, and these fibers are thought to be part of a 'ciliary pore complex' through which only selected proteins are allowed to enter the ciliary compartment [2].

In general, cilia are classified as motile $(9+2)$ or nonmotile $(9+0)$, where ' 9 ' refers to the number of outer doublet MTs present in the ciliary axoneme and ' 2 ' or ' 0 ' refers to the number of central MTs present. Motility requires the presence of axoneme-associated dynein arms to generate power, and for most motile cilia additional accessory structures, e.g. radial spokes and central pair projections, are involved in regulating dynein-mediated motility [3]. Some motile cilia, however, contain an extra central pair or lack the central pair entirely. For example, cilia with $9+4,9+2$, and $9+0$ axonemes have been observed on the notochordal plate of rabbit embryos and these axonemes all contain dynein arms, indicating that they are motile [4]. Consistent with this, $9+0$ monocilia on the embryonic mouse node, as well as $9+0$ cilia on Kupffer's vesicle in medaka fish, were observed to perform rotational beating in a manner that generates a directional flow across the cell surface, which is required for establishment of the left-right axis [5-7].

In mammals, numerous motile $9+2$ cilia are present on the surface epithelial cells lining the airways, brain ventricles, and oviducts. The main function of these $9+$ 2 cilia is to promote the movement of fluids or substances, e.g. airway surface liquid, cerebrospinal fluid, or egg cells, across the epithelial surface; failure to do so may result in airway disease, hydrocephalus, or sterility [8]. A single motile flagellum is present on the mammalian sperm cell, whereas the green alga Chlamydomonas, a commonly used model organism for studying ciliary assembly and function, contains two motile flagella that propel the cell towards or away from a light source $[8,9]$. In addition to their motile functions, $9+2$ cilia also have important sensory functions, which may in part play a role in regulating motility $[3,10]$. However, in terms of cilium-mediated signaling, it is the nonmotile $9+0$ cilia that have attracted the most attention in recent years.

Nonmotile $9+0$ cilia, also known as primary cilia, are present on most cells in the mammalian body (see http:// www.bowserlab.org/primarycilia/ciliumpage2.htm for a comprehensive list of cells known to possess primary cilia). Like motile $9+2$ cilia, the axoneme of $9+0$ cilia consists of 9 outer doublet MTs that are nucleated by the basal body, but the central MT pair and structures involved in motility (e.g. dynein arms, radial spokes) are lacking. The primary ciliary membrane is enriched for a number of receptors and ion channels, including platelet-derived growth factor receptor- $\alpha$ (PDGFR $\alpha)$, somatostatin receptor 3 , serotonin receptor 5 , melanin-concentrating hormone receptor 1 , polycystins 1 and 2, as well as components of the Hedgehog (Hh) and Wnt signaling pathways [10]. Therefore, the primary cilium is considered to function mainly as a sensory organelle ([11]; see also below). Some of the best examples of primary cilia that act as sensory organelles are the sensory cilia present in vertebrate olfactory organs and the outer segments of vertebrate photoreceptors. The latter are initially formed from primary cilia during development of the eye and remain connected to the inner segment in adult retina by a short 'connecting cilium' that is functionally and structurally equivalent to the transition zone of other types of cilia. The outer segment of photoreceptors turn over at a high rate and therefore large quantities of photo transduction proteins are continuously being transported from the inner to the outer segment, mainly via a process known as intraflagellar transport (IFT), which will be described in more detail below. Defects in IFT impair transport of photo transduction proteins from the inner to the outer segment and lead to degeneration of the outer segments, ultimately resulting in blindness [12]. Likewise, the dysfunction of the cilium on olfactory neurons leads to anosmia and results in their degeneration [13].

In addition to differentiated cells of olfactory and visual organs, cells of many other organs and tissues in our body (e.g. kidney, liver, pancreas, brain, and oviduct) also display $9+0$ primary cilia on their surface when the cells are in growth arrest. While these primary cilia are thought to serve as sensory 'antennae' that detect and transmit signals from the surrounding environment to the cell body in order to regulate embryonic development and tissue homeostasis in the adult $[10,11]$, there is a growing body of evidence suggesting that primary cilia also play a crucial role in cell cycle control. Since the primary cilium is subtended by the basal body, which is equivalent to one of the mitotic centrioles of the centrosome, a prerequisite for cell cycle entry is disassembly of the primary cilium, a tightly regulated and still not well understood process that appears to involve mitotic kinases such as Aurora and NIMA-related kinases [11, 14, 15]. Consistent with a role for primary cilia in growth 
control, defective primary cilia were hypothesized to be associated with cancers resulting from abnormal mitogenic signaling or von Hippel-Lindau tumor suppressor signaling $[16,17]$.

\section{Assembly of the Primary Cilium}

Assembly of the primary cilium begins in $G_{1}$ when Golgi-derived (primary) vesicles attach to the distal end of the older (mother) centriole of the centrosome. As ciliogenesis progresses, axonemal subunits are added directly onto the distal end of the mother centriole, and additional vesicles fuse with the primary vesicles eventually forming a membrane sheath around the nascent ciliary axoneme. In addition, the mother centriole acquires accessory structures and appendages that promote docking and attachment of the mother centriole to the apical plasma membrane of the cell [14, 18-20]. Following docking of the mother centriole to the apical membrane, the axoneme continues to elongate within the membrane-enclosed compartment by addition of axonemal subunits to the distal end of the growing ciliary axoneme. Because the ciliary compartment lacks the capacity for de novo protein synthesis, axonemal assembly depends on transport of ciliary precursors from the base of the cilium to its distal tip. This transport is carried out by IFT, which is essential for the assembly and maintenance of almost all eukaryotic cilia and flagella [2].

IFT is a highly conserved process initially discovered in Chlamydomonas as a bidirectional movement of groups of large protein complexes (IFT particles) along the ciliary axoneme [21]. Movement in the anterograde (base to tip) direction is mediated via kinesin-2 motors (Kif3a/ $\mathrm{Kif3b/KAP} \mathrm{complex} \mathrm{in} \mathrm{vertebrates),} \mathrm{whereas} \mathrm{movement}$ in the retrograde (tip to base) direction is mediated via cytoplasmic dynein 2 [2, 22-24]. These motors attach to the IFT particles, which in turn are thought to be associated with axonemal cargo proteins entering and leaving the cilium [25]. The IFT particles and motors as well as their cargo proteins accumulate near the site where transition fibers contact the ciliary membrane at the base of the cilium prior to entry into the ciliary compartment, and kinesin-2 then transports IFT particles, cargo proteins, and inactive cytoplasmic dynein 2 to the ciliary tip. At the tip, the IFT particles are remodeled, cargo is presumably unloaded, and kinesin- 2 becomes inactive while cytoplasmic dynein 2 becomes active and transports the IFT particles and ciliary turnover products back to the cell body for recycling $[2,22,23,26]$. The mechanisms that regulate IFT at the ciliary base and tip are not well understood, although some key proteins involved, e.g. MAP kinases and IFT172, have been identified [23, 24].

The IFT particles are composed of approximately 16 different polypeptides, which in Chlamydomonas can be separated biochemically into two distinct complexes termed complex A and B [27]. Almost all of the genes encoding IFT particle polypeptides have been cloned and sequenced, and bioinformatic analyses of IFT polypeptide sequences have revealed that many of them contain motifs and domains known to be involved in transient protein-protein interactions, similar to components of coat protein I and clathrin-coated vesicles [28, 29]. Functional studies of individual IFT particle proteins in diverse ciliated organisms have confirmed a requirement for these proteins in ciliary assembly, and have further indicated that components of IFT complex B are associated with anterograde IFT while components of IFT complex A primarily function during retrograde IFT $[23,26$, $28]$. For example, inactivation of the complex B polypeptide IFT88/Polaris, which is encoded by the ift 88 (previously called $\mathrm{Tg} 737$ ) gene, impairs primary cilium formation in the mouse, presumably because ciliary building blocks fail to enter the ciliary compartment via anterograde IFT [30]. In contrast, inactivation of the complex A polypeptide IFT139/THM1 in the mouse leads to the formation of stunted, bulbous cilia, presumably due to defective retrograde IFT resulting in accumulation of IFT particles within the cilium [31].

Because of their essential role in building the primary cilium, IFT proteins are required for appropriate functioning of a variety of cilium-mediated signaling pathways such as Hh [32] and PDGFR $\alpha$ [33] signaling. However, there is growing evidence that IFT also plays a more direct role in signaling, both in Chlamydomonas and in vertebrates, although the exact mechanisms involved are still somewhat obscure $[34,35]$.

\section{Introduction to Primary Cilia and Ciliopathies}

The finding that the gene whose function was disrupted in the Oak Ridge Polycystic Kidney mouse (ORPK mouse, ift $88^{\text {orpk }}$, or ift $88^{\text {Tg737NRpw }}$ ) encodes an ortholog of Chlamydomonas IFT88 was the eye opener for many cell and developmental biologists. The IFT88 mutant mouse revealed primary cilia function as important sensory devices that probe the extracellular environment and send on information to the cell body in order to control developmental processes and tissue homeostasis. Mutations in 
ift 88 in mice were known to cause a series of developmental defects [36], including cystic kidney disease, but the function of the gene was mysterious until its involvement in IFT and ciliary assembly was demonstrated. Thus in 2000, Pazour et al. [30] first showed that Chlamydomonas IFT88 is an ortholog of the previously characterized mouse $\operatorname{Tg} 737$ gene and demonstrated a role for IFT 88 in flagellar assembly. Consistent with these findings it was shown that primary cilia in the renal tubules [30] and cilia of the node [37] of $t g 737 / i f t 88$ mutant mice were abnormally short or missing, which suggested that PKD and defects in the establishment of left-right asymmetry during embryonic development could be ciliary diseases. Another key finding that further substantiated the link between cilia and PKD was the observation that GFPtagged versions of the Caenorhabditis elegans orthologs of mammalian polycystin 1 (PKD1) and polycystin 2 (PKD2) localize to ciliated endings of male sensory neurons [38]. This prompted other investigators to reexamine the subcellular localization of mammalian PKD1 and $\mathrm{PKD} 2$, leading to the demonstration that both of these proteins indeed localize to primary cilia in cultured human and mouse kidney cells $[39,40]$. While Chlamydomonas, C. elegans, and mice were crucial in establishing the first link between primary cilia and PKD, additional model systems have subsequently proven to be of great benefit for investigation of ciliary assembly, ciliopathies, and ciliary signaling. These other important model organisms include Tetrahymena, Drosophila, trypanosomes and zebrafish, which are easy to manipulate and analyze in the laboratory. Zebrafish has become an excellent genetic tool in the study of ciliary genes involved in vertebrate embryogenesis and human disease since its transparent embryo develops outside the mother's body and it has many of the same organ systems that are affected in human ciliopathies. Collectively, studies on several model organisms as well as cultures and tissues of mouse and human origin have not only provided important insight into the molecular mechanisms of PKD, but have also revealed a link between primary cilia and a growing list of other diseases and syndromes, including nephronophthisis (NPHP) and Bardet-Biedl, orofacial-digital type 1, Meckel-Gruber, and von Hippel-Lindau syndromes (fig. 1). Doubtless, many more ciliopathies will be added to this list, since limited information is available on primary cilia in many organs and tissues during development and in the adult.

Great attention has been given to the nephronal disorders arising from ciliary dysfunction such as $\mathrm{PKD}$, due to which a connection between ciliary malfunctions and aberrant tissue homeostasis was first hypothesized [30, $40,41]$. Both the autosomal dominant (ADPKD) and recessive (ARPKD) variants of PKD are characterized by the formation of large fluid-filled cysts and greatly enlarged kidneys that are associated with increased proliferation late in the disease process [42]. ADPKD is mainly due to mutations in the PKD1 and PKD2 genes, whereas ARPKD is caused by mutations in the gene encoding fibrocystin [42]. Another complex of recessive cystic kidney diseases is NPHP, resulting from defects in the genes encoding nephrocystin (Nphp) 1-9, and being the main genetic cause of end-stage renal failure within the first three decades of life. As opposed to PKD, tubular cyst

Fig. 1. Overview of primary cilia in signaling pathways and ciliopathies. a Scanning electron microscopy of a primary cilium (arrow) emanating from the surface of an hESC. The inset shows a cross-section of the hESC cilium with a $9+0$ microtubule ultrastructure analyzed by transmission electron microscopy (TEM). Reprinted from Kiprilov et al. [143] with permission from J.C.B. b TEM analysis of the structural relationship between the primary ciliary axoneme $(\mathrm{Ax})$, the distal (Dc) and proximal (Pc) centrioles and the Golgi apparatus $(\mathrm{G})$ in a chicken chondrocyte. Reprinted from Jensen et al. [97] with permission from Elsevier. c Immunofluorescence microscopy analysis of primary cilia [anti-acetylated $\alpha$-tubulin (tb), red, arrows] in cultures of growtharrested NIH3T3 cells. The nucleus was stained with DAPI (blue). Inset: An NIH3T3 primary cilium costained with anti-centrin-2 (green) that marks the two centrioles (asterisks). d List of various signal transduction systems being coordinated by the primary cilium. e Gross morphology (left panels) and histological sections (right panels) of a normal (top panels) and an ift $88^{\text {tm } 1 \text { Bky }}$ cystic kidney mutant (bottom panels) at 3 weeks of age. Tissue sections (right panels) were stained with hematoxylin and eosin. $\mathbf{f}$ List of proposed ciliopathy phenotypes and human syndromes caused by defects in assembly or function of primary cilia in mammals. g Schematic overview of signal transduction systems being coordinated by the primary cilium and the centrosome in regulation of cell proliferation, survival, polarity, migration and differentiation. Activation of transmembrane receptors [e.g. by interaction with ECM, by binding to soluble ligands such as PDGF-AA (see also fig. 2a) and morphogens, or due to mechanostimulation (see also fig. 2c)] (1) leads to activation of effector molecules in the cilium (2) or at the centrosome (3) followed by activation of specific transcription factors for de novo gene expression (4). Effector molecules may also activate downstream components in signal transduction independent of the nucleus in regulation of cellular processes. As part of this, there is a continuous turnover of transmembrane receptors in the cilium, partly regulated by effector molecules, that controls the trafficking of signaling components into and out of cilium (see also fig. 2b) (5), such as the concerted movement of Ptc out of and Smo into the cilium in response to Hh stimulation. $\mathrm{PM}=$ Plasma membrane. 
formation in NPHP does not result in enlarged kidneys, but phenotypic characteristics include degradation of tubular basement membranes, tubular collapse, and interstitial fibrosis [43-45]. The cystic kidney phenotype in NPHP is frequently combined with other defects such as cerebellar hypoplasia and ataxia in Joubert syndrome, or retinitis pigmentosa in Senior-Løken syndrome [43-45]. Interestingly, the phenotype in NPHP-2 patients with mutations in the INVS gene that encodes inversin has an earlier onset than the other NPHP types, and combines the phenotypic characteristics of NPHP, such as renal interstitial and glomerular fibrosis and tubular cysts, with features of ADPKD, including enlargement of the kid- neys due to cysts outside of the medullary region [46]. Moreover, microarrays and immunoblotting analysis of kidneys from mice containing a homozygous carboxyterminal deletion of invs showed increased proliferation and cell cycle progression as compared to wild-type mice [47].

Many proteins whose functions are disturbed in cystic diseases have been localized to the cilium or the ciliary basal body, where they might contribute to regulating kidney development and function. Included herein are the polycystins $[39,40]$, the nephrocystins [46, 48-57], fibrocystin [58], and proteins regulating Wnt signaling and planar cell polarity [59-62], which in different ways coordi-
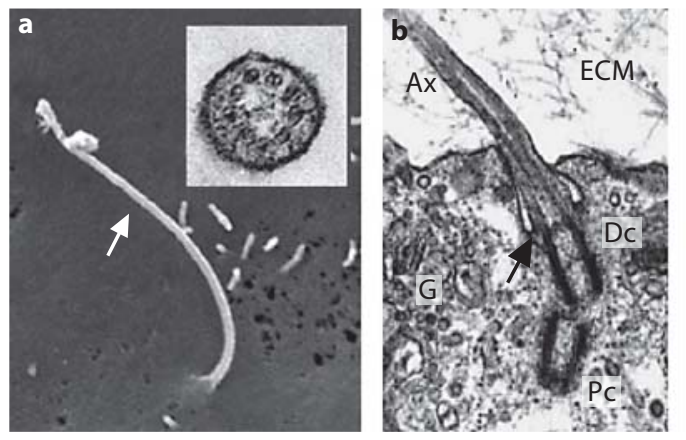

d Examples on signaling systems coordinated by primary cilia

- TRP ion channels and $\mathrm{Ca}^{2+}$ signaling

- Mechano- and osmosensing

- Wnt signaling

- Hh signaling

- Receptor tyrosine kinase (RTK) signaling

- Neurotransmission

- Extracellular matrix signaling

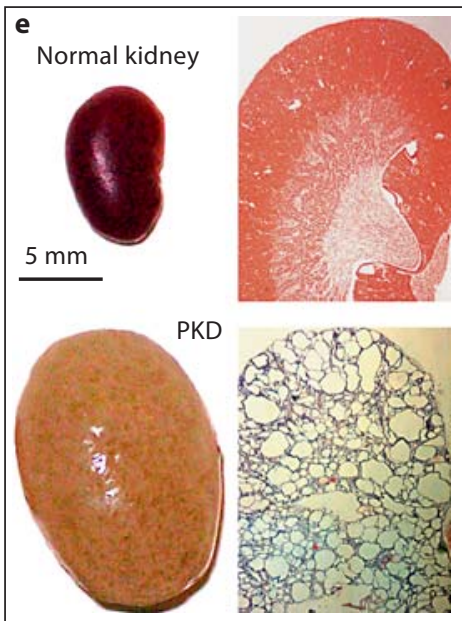

f Proposed ciliopathies and syndromes (primary cilia)

- Cystic diseases in kidney, pancreas and liver (e.g. PKD and NPHP)

- Skeletal patterning defects (e.g. polydactyly، brachydactyly)

- Anosmia

- Hydrocephalus, exencephalus

- Situs inversus

- Cognitive defects

- Hyperphagia/obesity

- Diabetes

- Retinitis pigmentosa

- Skin diseases

- Impaired wound healing

- Cancer

- Atherosclerosis and hypertension

- Embryonic death

Examples on proposed syndromes

- Bardet-Biedl syndrome

- Kartagener's syndrome

- Oro-facial-digital type 1 syndrome

- Meckel-Gruber syndrome

- Von Hippel-Lindau syndrome

- Senior-Løken syndrome

- Alström syndrome

- Usher syndrome

- Joubert syndrome

- Ellis-van Creveld syndrome

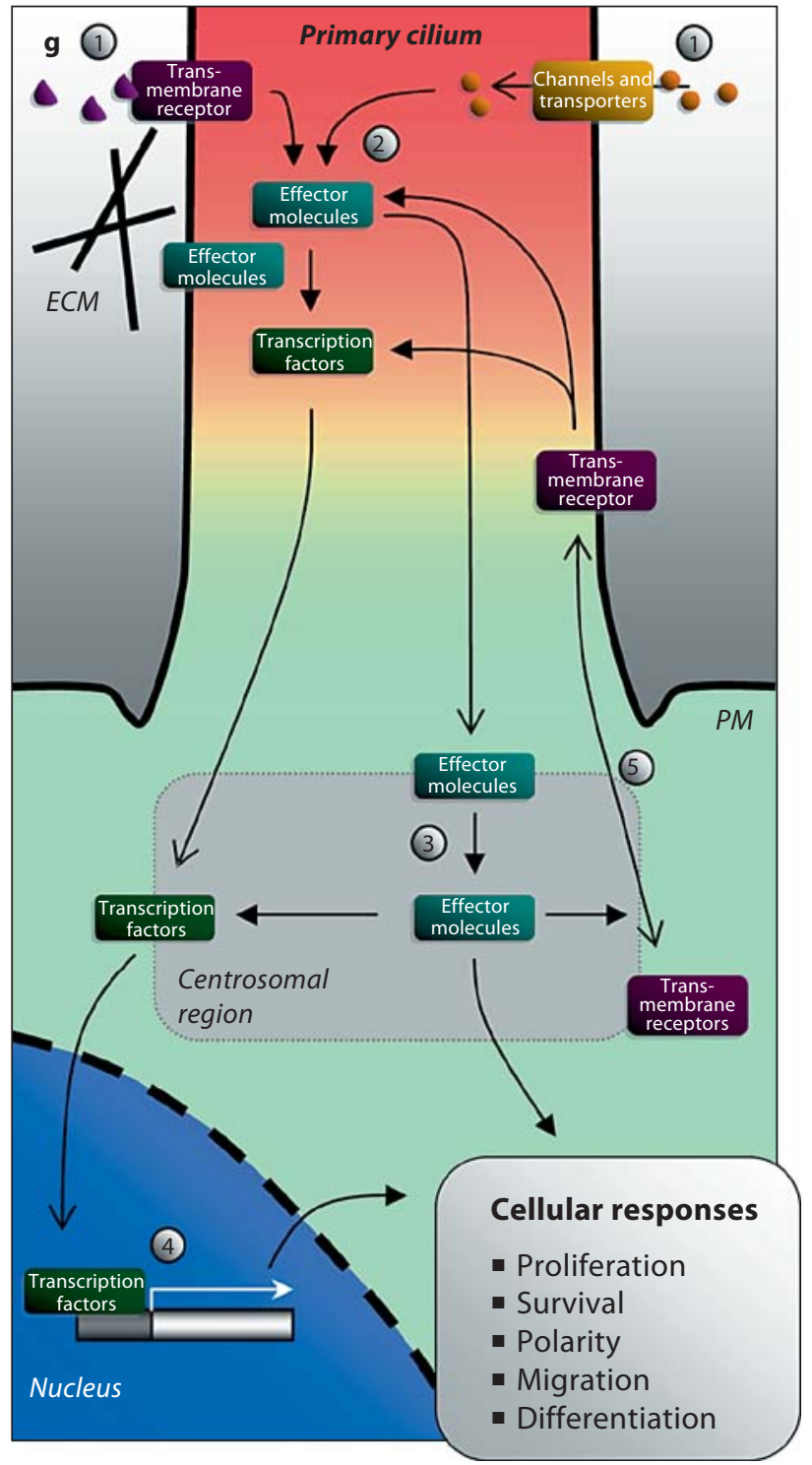



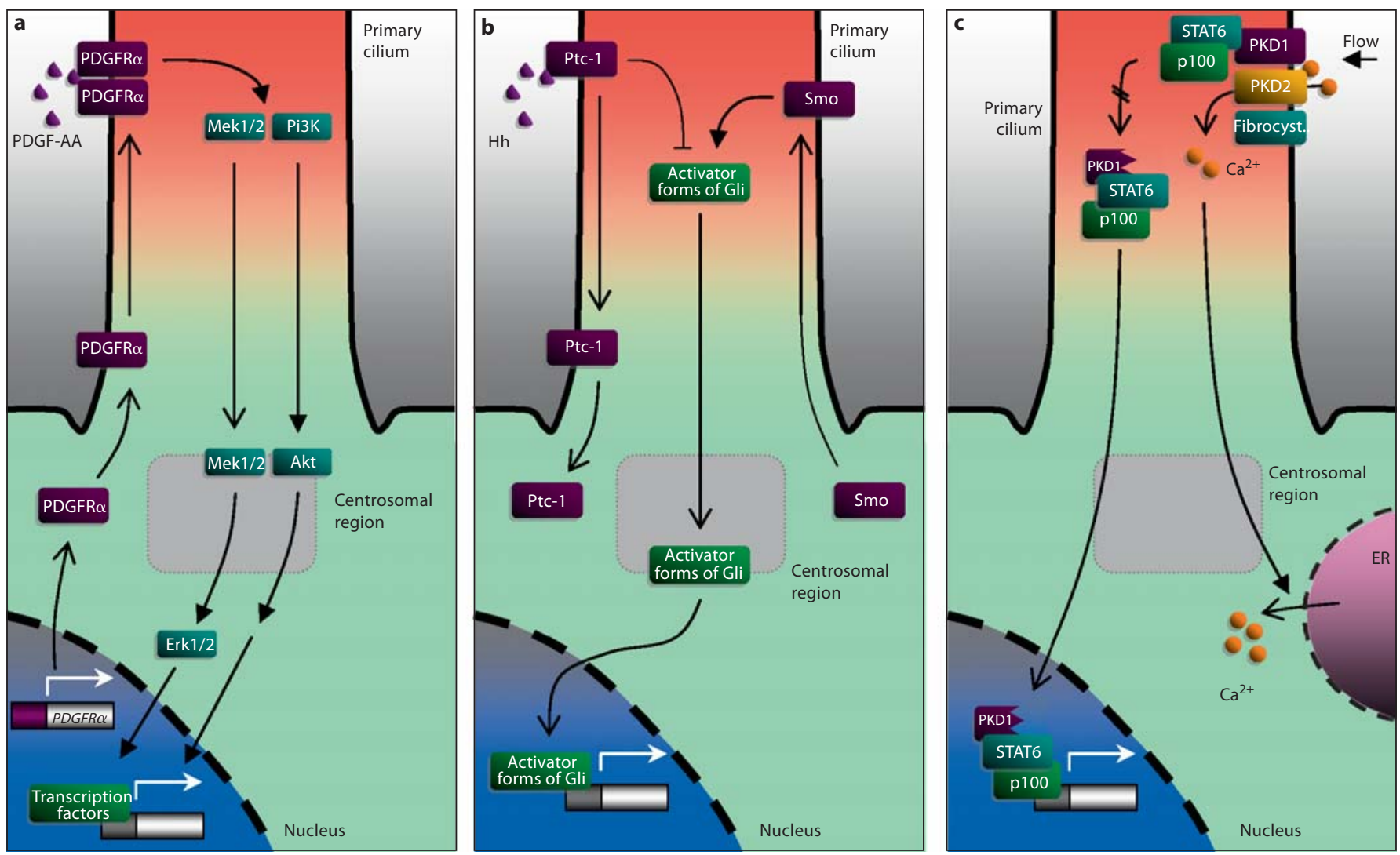

Fig. 2. Simplistic models of different signaling systems coordinated by the primary cilium. a Ciliary PDGFR $\alpha \alpha$ signaling. Upon growth arrest expression of PDGFR $\alpha$ is up-regulated and the receptor is targeted to the primary cilium. Stimulation with PDGFAA leads to PDGFR $\alpha$ homodimerization in the cilium followed by activation of PI3K/Akt and Mek1/2-Erk1/2 pathways, leading to cell migration and transcriptional control of cell cycle entry. b Ciliary Hh signaling. Binding of Hh ligands to Ptc-1 in the primary cilium results in translocation of Ptc-1 out of the cilium and targeting of Smo into the cilium. This favors the formation of active forms of Gli transcription factors which may occur in the

cilium followed by translocation of the active Gli forms to the nucleus for activation of the Hh response. c Bending of the primary cilium by fluid flow leads to activation of the PKD1/2 complex in the cilium and influx of $\mathrm{Ca}^{2+}$ into the cilium followed by activation af $\mathrm{Ca}^{2+}$ channels in endoplasmic reticulum (ER). Fibrocystin may assist PKD2 function. In the absence of ciliary bending, PKD1 is proteolytically cleaved and the C-terminus translocates to the nucleus in a protein complex with p100 and STAT6 to activate transcriptional activity in cystic diseases. Please see text for references.

nate a series of signal transduction pathways in the kidney. It was proposed that $\mathrm{PKD} 1$ and $\mathrm{PKD} 2$ form a protein complex in the primary cilium to function as a mechanosensor to elicit a calcium signal in response to fluid movement through the renal tubules [63] (fig. 2), where loss of cilia or mutations in the polycystins lead to cyst formation. In line with this, earlier studies showed that bending of primary cilia in cultures of renal epithelial duct cells by fluid shear or mechanical stimulation causes intracellular $\mathrm{Ca}^{2+}$ to increase [64-66]. This suggests that ciliary mechanotransduction is important for normal function of the kidney epithelium and that loss of the cilium leads to PKD.

More recent studies in mice have revealed that the rate of cyst formation and cystic disease severity are dependent on the time point when cilia or polycystin function is disrupted $[67,68]$. Using conditional alleles of ift 88 , kif3a (component of the heterotrimeric IFT kinesin-2 motor complex), or PKD1, and inducible Cre deletor mouse lines, it was shown that disruption in early postnatal life (P1-P12) results in rapid cyst formation within 3 weeks of loss of the gene. In contrast, if cilia or polycystin-1 function is disrupted after P12, cyst formation requires 6 months to a year to form. Another surprising finding from these studies was that there was no marked increase in proliferation rates between the mutant and 
control kidneys, even in the cystic animals where function was disrupted in perinatal periods. Together these data indicate that there is a critical time point at which cilium dysfunction causes a rapid- or slow-progressing cystogenic phenotype and raised concern about the simple pathogenic model whereby loss of cilium-mediated mechanosensation is the cause of cyst formation. In further studies, it was revealed that this switch point might be associated with completion of renal differentiation, which occurs at about 2 weeks of age in mice, changes in the proliferative environment, and a large change in the gene expression profile that occurs at around P12.

The importance of having a proliferative environment for cyst formation in the cilium mutants was analyzed by inducing cilium loss in adult mice followed by renal injury through obstruction or ischemic reperfusion. This injury reinitiates proliferation in the adult kidney as part of the repair process and was found to result in rapid cyst formation similar to that seen in the perinatally induced cilium mutants. Cysts were not present in the contralateral noninjured cilium mutant kidney. A possible mechanism connecting ciliary dysfunction, cell proliferation, and cyst formation was further defined by studies by Fischer et al. [69]. They showed that mitotic spindles in the perinatal kidney normally align along the axis of the nephron such that cell divisions increase nephron length. In contrast, in cystic disease mouse and rat models the orientation of cells divisions occurs randomly, with many resulting in expansion of the diameter of the nephron. Deletion of the ciliary protocadherin and planar cell polarity (PCP) protein Fat4 was recently shown to elicit a similar disruption of spindle orientation during renal tubular elongation in mice [61]. Thus, these data suggest that cilia or the basal body are needed for normal orientation of the spindle. Whether this is in response to fluid flow and the polycystin-generated calcium signal, and how this is coupled to PCP has yet to be fully explained.

\section{Signaling Pathways Coordinated by the Primary Cilium}

In normal tissues, the primary cilium coordinates a series of signal transduction pathways, including the $\mathrm{Hh}$, Wnt, and PDGFR $\alpha$ pathways, and also functions as a photo-, mechano- and osmosensing unit that probes and relays information from the extracellular environment into the cell. In many cases, proper signaling is tightly coupled to the correct translocation of receptors and downstream effector molecules involved in signal transduction to the cilium. We still know very little about the mechanisms that control trafficking of signal components into and out of the cilium, although IFT is likely to be involved in several aspects of receptor trafficking [23, 34, 35]. Further, a single primary cilium may contain many different signal transduction systems in order to carry out diverse signaling processes in tissue development and homeostasis. Therefore, it is likely that the composition of signal systems closely reflects the functionality of the cell type in different tissues, i.e. that some ciliary signal systems are tissue specific. This may be particularly relevant when comparing cilia situated deep inside various tissues and organs versus cilia that protrude from the apical surface into the lumen of e.g. tubular structures as seen on epithelial and endothelial cells (ECs). Also, during development, the composition of ciliary signal systems may change as part of the dynamic process that controls cell differentiation, allocating different signal systems to different cell types to determine cell fate and function.

In the following we will present a brief overview of some of the signal transduction pathways that have been shown to be coordinated by the primary cilium to control cellular processes during development and in tissue homeostasis.

\section{Signaling in Primary Cilia on Epithelial and \\ Endothelial Cells}

As outlined above, PKD1 and PKD2 may form a mechanosensory complex that coordinates a flow-sensing response in kidney primary cilia. However, ciliary polycystins may well have other functions in relaying this response to control kidney development and homeostasis [42]. The channel activity and positioning of PKD2 in the cilium is regulated by fibrocystin, which is indirectly linked to the $\mathrm{N}$-terminus of PKD2 through Kif3a/b of the kinesin 2 complex [70-73]. In addition to their role in $\mathrm{Ca}^{2+}$ signaling, the polycystins contribute to maintaining homeostasis through p53 and JNK [74] and also negatively regulate the JAK/STAT $[75,76]$ and the mTOR pathways [77]. Alterations in mechanostimulation induce cleavage of PKD1, releasing tuberin and mTOR from their flow-dependent inhibition by PKD1 [77], and allowing the transcription factor STAT6 and cofactor P100 to translocate from the cilium to the nucleus [76]. By itself, the PKD1 C-terminal fragment may influence gene transcription and perhaps modulate Wnt signaling [76, 78, 79], all processes that promote dedifferentiation and proliferation [for a review, see 80].

The nephrocystins are also assumed to exert their function through the primary cilium in renal develop- 
ment and maintenance, although the exact mechanisms remain elusive [43-45]. More than half of the Nphps (1, $4,5,6$ and 8 ) have been localized specifically to the ciliary transition zone at the base of the cilium, suggesting a role in ciliary assembly and/or transport of specific proteins into the ciliary compartments $[48,50,52-54,56,57]$. As such, Nphp-1 and Nphp-4 have also been proposed to play a role in axonemal or IFT modeling [81], whereas Nphp-9/Nek8 is necessary for expression and ciliary positioning of PKD1 and PKD2 [82, 83]. Nphp-3 may also impact on ciliary length in mammalian cells $[81,84]$, and was recently demonstrated to interact directly and genetically with Nphp-2/inversin in the establishment of bilateral asymmetry and promotion of tissue polarity [ 84 , 85]. The latest hypothesis proposes the existence of one or more nephrocystin complexes at the ciliary transition zone, in line with the BBSome, which may interact with or be part of a ciliary pore complex $[43,45,56,86]$. In addition, the activation of the transcription factor ATF4/ CREB-2 by Nphp-6/CEP290 [55] indicates that the actions of the nephrocystins are complex and may affect ciliary functions on several levels. Furthermore, studies of Nphp-2 and Nphp-3 $[84,85]$ as well as recent findings with ift $88, k i f 3 a$, and bbs mutants $[62,87]$ suggest an important role for the primary cilium in regulating Wnt signaling, which will be described in further detail below.

Primary cilia on cholangiocytes that extend from the epithelium into the bile duct lumen also possess a series of receptors and signaling molecules that control tissue homeostasis. These include PKD1, PKD2, fibrocystin, TRPV4, and G-protein-coupled purinergic receptor, $\mathrm{P}_{2} \mathrm{Y}_{12}$, that ultimately coordinate mechano-, osmo-, and chemo-sensory functions, which when defective cause, e.g., cystic and fibrotic liver diseases [88]. Primary cilia on endothelial cells (EC) of the blood vessels and in endocardium were proposed to function as shear stress sensors. In cultured human umbilical vein ECs, cilia were found to disassemble in response to laminar shear stress [89]. PKD1 strongly localized to EC cilia in embryonic mouse aorta. In cultures of embryonic ECs, fluid shear stress cleaves PKD1, and ultimately leads to changes in $\mathrm{Ca}^{2+}$ signaling and nitric oxide synthesis [90] as well as expression of shear-responsive genes such as Krüppel-like factor-2 [91]. Consequently, dysfunctional cilia in the cardiovascular system may increase the risk for artherosclerosis and hypertension $[90,92]$.

\section{PDGFR $\alpha$ Signaling in Cycle Control and Migration}

Signaling via PDGFs and PDGFRs plays an essential role in cell survival, growth control and cell migration during gastrulation, fetal development and in maintenance of tissues in the adult, with defects causing a range of diseases, including cancer, vascular disorders and fibrosis [93]. Recently, it was shown that PDGFR $\alpha$ signaling is coordinated by the primary cilium in mouse embryonic fibroblasts (MEFs), i.e., expression of PDGFR $\alpha$ is upregulated during growth arrest and targeted to the cilium where PDGF-AA-dependent activation of the receptor and its initial downstream effectors such as Mek1/2 and Akt occurs [33, 94] (fig. 2). In wild-type cells these signaling events stimulate cell cycle entrance, which is

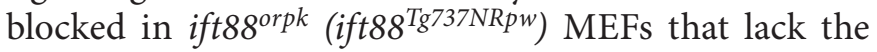
primary cilium [33]. Consequently, PDGFR $\alpha$ signaling through the fibroblast primary cilium may be important in tissue homeostasis while perturbations in this pathway could lead to oncogenesis.

The fibroblast primary cilium may function as a cellular GPS that coordinates directional migration and PDGFR $\alpha$-mediated chemotaxis. Using micropipettes to generate a PDGF-AA gradient wild-type growth-arrested MEFs respond immediately to PDGF-AA injection, and migrate uniformly towards the pipette, while ift $88^{\text {orp }}$ k MEFs do not respond to PDGF-AA and move around randomly. In in vitro wound-healing assays, primary cilia in wild-type MEFs orient parallel to one another, perpendicular to the wound, and incubation with PDGF-AA increases the migration speed and the directional movement of the cells. In contrast, in ift $88^{\text {orpk }}$ cells, the migration speed is unaffected by PDGF-AA incubation, and cells have decreased directionality [94]. PDGFR $\alpha$-mediated migration is associated with activation of the ubiquitous plasma membrane $\mathrm{Na}^{+} / \mathrm{H}^{+}$exchanger, NHE1, and inhibition of NHE1 reduces PDGF-AA-mediated cell migration speed and directionality of wild-type MEFs, whereas this inhibition is markedly reduced in ift $88^{\text {orp } k}$ MEFs [95]. These results support the conclusion that the primary cilium represents an alternative mechanism of sensing chemotactic gradients and is part of the positioning machinery that coordinates directed migration in wound healing and developmental processes.

Primary cilia may also directly interact with extracellular matrix (ECM) proteins as the cell moves, transmitting mechanical information from the outside milieu to the cell. In vascular smooth muscle cells, primary cilia that contain PKD1, PKD2 and integrins are critical for cell-ECM interaction and mechanosensing that allow the cilia to project into the ECM and potentially control wound healing [96]. Also, in chondrocytes primary cilia make direct physical contact with ECM components via specific ECM receptors, suggesting that mechanical stim- 
uli may be transmitted through the cilium to control tissue development and to construct a mechanically robust skeletal system [97, 98]. Although speculative at this point, the directional migration of fibroblasts may also be similarly regulated through interactions between the cilium and ECM, and potentially in concert with chemoattractants in embryonic patterning and adult tissue reorganization.

\section{Wnt Signaling}

As indicated above, the primary cilium has been proposed to have a role in Wnt signaling that regulates cell proliferation, cell fate determination, and migration. Recently, Wnt signaling was described as a network of interacting rather than individual pathways [99]. Traditionally, Wnt signals are divided into at least three distinct pathways, all initiated by binding of a ligand of the Wnt family to a 7-transmembrane Frizzled (Fz) receptor. Canonical Wnt signaling involves Dishevelled (Dvl)-mediated stabilization of $\beta$-catenin, which serves as a transcriptional coactivator and in turn induces cell cycle progression, proliferation, differentiation, and growth in addition to migration and regulation of embryonic development [100]. Noncanonical, or $\beta$-catenin-independent Wnt signaling pathways act through aPCK, CamK and JNK to control cellular polarity, migration and PCP, necessary for convergence extension during, e.g., gastrulation and neurulation [for a review, see 101].

The primary cilium and basal body have been assigned a role in regulating both the canonical and the noncanonical Wnt signaling pathways due to the ciliary/basal body localization of the PCP proteins inversin [49, 85], Vangl-2 [102], and Fat4 [61], in addition to members of the degradation complex, GSK-3 $\beta$ [59] and APC [62]. Vangl-2 appears to interact with Prickle-1 and inversin [85], both of which can suppress Wnt $/ \beta$-catenin signaling through Dvl degradation $[85,103]$, the latter in concert with another ciliary protein, nephrocystin-3, as mentioned above [84]. PCP-like phenotypes have been observed in the inner ear of mice where ift 88 has been disrupted [104], and in Bbs4deficient mice and zebrafish [102]. Further, loss of primary cilia in the ift $88^{\text {orpk }}$ mouse causes a series of abnormalities in the pancreas, including extensive cyst formation in ducts associated with defects in cell cycle control $[105$, 106]. In the dilated ducts and cysts, the cytosolic localization of $\beta$-catenin is increased and there is an increased expression of Tcf/Lef [105], which activates transcription of Wnt target genes [107-109]. These observations support the conclusion that primary cilia are associated with the regulation of Wnt signaling in the pancreas.
More recently, two different approaches were used to disrupt cilia/basal body function and demonstrated the importance of these structures for the regulation of canonical Wnt signaling $[62,87]$. RNAi-induced basal body disruption impaired gastrulation in zebrafish due to obstructed convergence extension movements, and was accompanied by moderately increased canonical signaling. The latter was also the response to shRNA knockdown of either BBS4 or BBS6/MKKS in HEK293 cells, which impaired the ability of noncanonical WNT5a to suppress the canonical Wnt3a activity. An identical effect was seen in cells where cilia were ablated by knockdown of KIF3A with shRNA [87]. A corresponding hyperresponse to Wnt3a was observed in kif3a or ift $88^{\text {orpk }}$ MEFs using a BATgal canonical Wnt reporter as well as in MEFs and Ofd1-deficient murine embryonic stem cells (mESCs), albeit not in the absence of Wnt3a [62]. In vivo there was a general increase in canonical Wnt signaling activity in kif3a mutants, although spatially the activity was normal. The phenocopying of these effects by specific inhibition of the proteasomal subunit RPN10, which associates with BBS4 [87], suggests that proteasomal targeting of $\beta$ catenin is a process that requires the basal body. Notably, whereas basal body disruption impaired noncanonical signaling and convergence extension [87], the noncanonical Wnt5a was still able to induce cytoskeletal rearrangements indicative of PCP equally well in heterozygous and kif3a-/- MEFs [62], suggesting that repression of the canonical pathway and activation of noncanonical Wnt signal are two independent processes involving the cilium or basal body. Further insights into the connection between cilia/basal body and Wnt signaling have been revealed by Bergmann et al. [84], who demonstrated that Nphp3 binds to inversin and can inhibit inversin-mediated canonical Wnt signaling.

\section{Hh Signaling}

Another critical signal transduction pathway that is coordinated by the primary cilium is the Hh pathway. In addition to its general roles in tissue homeostasis, this pathway is crucial in tissue differentiation during embryonic development, and dysfunction of the Hh pathway is responsible for, e.g., basal cell carcinoma, the most common form of cancer in humans.

In mammals, the Hh ligand comes in three different varieties [sonic (Shh), Indian (Ihh) and desert (Dhh)] that are spatially and temporally regulated and whose concentration gradient ultimately helps determine the eventual cell fate and proliferation rate [for a review, see 110]. The ligands work through two transmembrane proteins, 
Patched (Ptc) and Smoothened (Smo), that in turn regulate the activity of three transcription factors of the Gli family (Gli1, 2, 3) [111]. Ptc is the receptor for Hh ligands, and in the absence of $\mathrm{Hh}$ ligands it negatively regulates $\mathrm{Hh}$ signaling by suppressing the activity of Smo. Upon binding of $\mathrm{Hh}$ ligand to Ptc, the inhibition of Smo is relieved, preventing processing of Gli3 to a repressor and activating the Gli-2 transcription factor, which in turn induces the Hh pathway through their nuclear transcriptional targets [112].

A series of observations have now shown that primary cilia are critical regulators of the Hh pathway where the regulated concerted movement of Ptc out of and Smo into the cilium may create a switch by which cells can turn $\mathrm{Hh}$ signaling on and off during development and in control of tissue homeostasis [for reviews, see 111, 113]. In this scenario, binding of ligands to Ptc in the cilium activates the Hh pathway by removal of Ptc from the cilium [114] in a process that is associated with ciliary enrichment of Smo [115] (fig. 2). In vitro activation of Smo in cells exposed to Shh is shown to be blocked in MEFs lacking IFT172 or the dynein retrograde motor, Dync2h1 [116]. The translocation of Smo into the primary cilium upon Shh stimulation can also be blocked by knocking down Kif3A or $\beta$-arrestins, which are thought to be adapter proteins for the Smo protein [117].

Mutations in IFT proteins required for ciliary assembly results in dysfunctional Hh signaling and severe developmental disorders in mammals [for a review, see 111]. Removal of Kif3A causes aberrant Hh signaling which has been shown to have an impact on skeletogenesis [118, 119], neural tube formation [120], and cerebellar development $[121,122]$. Mutations in the IFT139 homologue (Thm1) specifically result in abnormal Gli3 activator/repressor ratios which in turn result in defects in neural tube formation [31]. Similarly, mutations in a basal body protein $(\mathrm{Ftm} 1)$ also resulted in abnormal ratios of Gli3 activator/repressor which lead to defects in left-right symmetry, neural tube formation and limb development [123]. The inhibition of Gli3 cleavage for subsequent activation of the Hh pathway was shown to also require other ciliary proteins: the retrograde IFT dynein motor subunit, Dnchc2 [124], the IFT172 protein [125] and the ciliary Arl13b (a small GTPase of the Arf/Arl family) [126]. Recently, a siRNA screen identified different mediators of the Hh pathway, among the genes controlling ciliogenesis: Nek1 (NIMA-like kinase) and Prka (a kinase participating in miRNA processing and thought to localize at the base of the cilium) [127]. Further, deletion of ift88 in ovary using Cre-Lox recombination in mice re- sulted in a severe delay in mammary gland development and defects in ovarian function [128]. Further, in IFT57deficient mice, there were defects in ventral neural tube formation (exencephaly) due to aberrant Shh signaling [129]. These findings highlight the importance of IFT proteins in the Hh pathway.

One example of the in vivo changes in the levels of $\mathrm{Hh}$ molecules in the cilium comes from studies on the development of the pancreas, which is controlled by the graded response to Hh signaling [130-133]. Interestingly, Smo and Gli2 are absent from pancreatic primary cilia at human embryonic stage week 7.5, i.e. before the formation of the endocrine system, but highly concentrated in cilia in 14- and 18-week-old fetuses [134]. This increase in ciliary localization of Smo and Gli2 is accompanied by loss of Gli3 in ductal epithelium, suggesting that a graded $\mathrm{Hh}$ signaling response coordinated by the primary cilium regulates the development of the human pancreas. Therefore, disruption of pancreatic development in mice with defects in primary cilia $[105,106,135]$ may be due to loss of both coordinated Hh and Wnt signaling during genesis of the pancreas. The canonical Wnt and Ihh pathways may also help to coordinate osteoblast and chondrocyte differentiation during bone development $[136,137$; for reviews, see 138, 139]. One known disorder resulting from developmental skeletal problems is chondroectodermal dysplasia in Ellis-van Creveld syndrome, which arises from mutations in Evc, which localizes to the base of the chondrocyte primary cilium [140].

\section{Stem Cells and Primary Cilia}

Stem cells hold great promises for their potential therapeutic abilities. Starting off in the pluripotent states, they have the potential to give rise to all three germinal layers and can differentiate to form specific cell types dependent on the environment and specific factors present. Thus far, it is thought that they could be used for therapies directed against Alzheimer's disease, Parkinson's disease, diabetes, and a host of other conditions [141]. Also, a credible paradigm has stem cells as important targets against cancer since cancer stem cells are the true progenitors of cancers [142].

Recently, human embryonic stem cells (hESCs) were shown to possess primary cilia with the classic $9+0$ architecture. Furthermore, it was shown that the Hh pathway was functional through the primary cilium as evidenced by the movement of Smo into and Ptc out of the primary cilium upon treatment with an agonist [143]. 
This implies that primary cilia could play pivotal roles in the earliest stages of development in terms of cell differentiation and proliferation. In addition, PDGFR $\alpha$, which helps maintain hESCs in an undifferentiated state [144], and components of the Wnt signaling cascade, which maintains the self-renewal in both mESCs and hESCs [145], have been shown to localize to the primary cilia and/or in the centrosomal region at the base of the cilium of hESCs [146]. Further, it was reported that the traditional stem cell markers (Oct4, Sox2, and Nanog) localize to the primary cilium in a subpopulation of cultured hESCs [146]. While their exact function in the cilium is not known, one hypothesis is that processing of these transcription factors could occur in the primary cilium analogous to that suggested for the Gli proteins. These data further hint at the critical role of the primary cilium in coordinating pathways determining cell differentiation and proliferation.

In later stages of development, it has now been reported that the primary cilia are critical for the development of neural stem cells needed for proper development of the hippocampal region. In mice lacking the Kif $3 \mathrm{~A}$ or the Smo proteins, there is a failure in the maturation of radial astrocytes, which would normally develop in the dentate gyrus and be responsible for maintenance of adult neurogenesis [147]. Similarly, removal of either of these proteins from the cerebellar granule cell precursors results in the improper development of the cerebellum [121]. A similar effect is seen when the IFT88 protein is knocked down [122]. Cilia are also important for proper neurogenesis in the hippocampal region as shown in mutants lacking the stumpy protein (Gli3 processing was altered). Knocking down the Smo or Shh proteins was also shown to lead to a failure in the development of the neocortex [148]. Postnatally, this leads to a lack of a specific subtype of neural stem cells [149].

\section{Conclusions}

Recent research in primary cilia and their function in coordinating cellular signal transduction pathways, developmental processes and tissue homeostasis have moved this organelle to a central position in human pathophysiology. While PKD was one of the first diseases to be linked to dysfunctional primary cilia, defects in these organelles have subsequently been associated with many other phenotypes, including cystic pancreatic and liver diseases, retinitis pigmentosa, anosmia, defective neurogenesis, polydactyly, and other developmental de-

fects now referred to as the ciliopathies, and there are also indications that the primary cilium is important in behavioral and mental disorders and oncogenesis. Recent work has further shown that stem cells possess primary cilia with signal transduction components that control maintenance of stem cell pluripotentiality and regulate early differentiation and proliferation. These findings imply that primary cilia play pivotal roles in the earliest stages of embryonic development, which could be important in regenerative medicine. Future studies on the mechanisms in ciliary assembly, translocation of signal components in and out of the cilium and coordination of ciliary signaling transduction pathways in developmental processes and tissue homeostasis will add further and important insight into the intrinsic biology of primary cilia in human health and disease.

\section{Acknowledgements}

This work was supported by the Lundbeck Foundation (No. R9-A969), the Novo Nordisk Foundation, the Danish Natural Science Research Council (No. 272-07-0530 and No. 272-07-0411 to S.T.C. and L.B.P.), a Novo Nordisk/Novozymes Scholarship (I.R.V.), the Lundbeck Foundation (No. 150/05 to A.A.), and NIH RO1 DK065655 and HD050327 (B.K.Y.). We apologize to those whose work is not described in this review owing to restricted space.

References

Nephron Physiol 2009;111:p39-p53 825 . 422 . 644
1 Gilula NB, Satir P: The ciliary necklace: a ciliary membrane specialization. J Cell Biol 1972;53:494-509.

2 Rosenbaum JL, Witman GB: Intraflagellar transport. Nat Rev Mol Cell Biol 2002;3:813-

-3 Salathe M: Regulation of mammalian ciliary beating. Annu Rev Physiol 2007;69:401-

$\checkmark 4$ Feistel K, Blum M: Three types of cilia including a novel $9+4$ axoneme on the notochordal plate of the rabbit embryo. Dev Dyn 2006;235:3348-3358.

5 Nonaka S, Tanaka Y, Okada Y, Takeda S, Harada A, Kanai Y, Kido M, Hirokawa N: Randomization of left-right asymmetry due to loss of nodal cilia generating leftward flow of extraembryonic fluid in mice lacking KIF3B motor protein. Cell 1998;95:829-837.

6 Okada Y, Takeda S, Tanaka Y, Belmonte JC, Hirokawa N: Mechanism of nodal flow: a conserved symmetry breaking event in leftright axis determination. Cell 2005; 121:633-

7 Hirokawa N, Tanaka Y, Okada Y, Takeda S: Nodal flow and the generation of left-right asymmetry. Cell 2006;125:33-45. 
8 Ibanez-Tallon I, Heintz N, Omran H: To beat or not to beat: roles of cilia in development and disease. Hum Mol Genet 2003;12:R27R35.

$\checkmark 9$ Silflow CD, Lefebvre PA: Assembly and motility of eukaryotic cilia and flagella. Lessons from Chlamydomonas reinhardtii. Plant Physiol 2001;127:1500-1507.

10 Christensen ST, Pedersen LB, Schneider L, Satir P: Sensory cilia and integration of signal transduction in human health and disease. Traffic 2007;8:97-109.

$\checkmark 11$ Pazour GJ, Witman GB: The vertebrate primary cilium is a sensory organelle. Curr Opin Cell Biol 2003;15:105-110.

$\checkmark 12$ Insinna C, Besharse JC: Intraflagellar transport and the sensory outer segment of vertebrate photoreceptors. Dev Dyn 2008;237: 1982-1992.

-13 Kulaga HM, Leitch CC, Eichers ER, Badano JL, Lesemann A, Hoskins BE, Lupski JR, Beales PL, Reed RR, Katsanis N: Loss of BBS proteins causes anosmia in humans and defects in olfactory cilia structure and function in the mouse. Nat Genet 2004;36:994-998.

14 Pan J, Snell W: The primary cilium: keeper of the key to cell division. Cell 2007;129: 1255-1257.

15 Quarmby LM, Parker JD: Cilia and the cell cycle? J Cell Biol 2005; 169:707-710.

16 Mans DA, Voest EE, Giles RH: All along the watchtower: is the cilium a tumor suppressor organelle? Biochim Biophys Acta 2008; 1786:114-125.

$\checkmark 17$ Christensen ST, Pedersen SF, Satir P, Veland IR, Schneider L: The primary cilium coordinates signaling pathways in cell cycle control and migration during development and tissue repair. Curr Top Dev Biol 2008;85:261301.

-18 Dawe HR, Farr H, Gull K: Centriole/basal body morphogenesis and migration during ciliogenesis in animal cells. J Cell Sci 2007; 120:7-15.

19 Sorokin S: Centrioles and the formation of rudimentary cilia by fibroblasts and smooth muscle cells. J Cell Biol 1962;15:363-377.

-20 Pedersen LB, Veland IR, Schrøder JM, Christensen ST: Assembly of primary cilia. Dev Dyn 2008;237:1993-2006.

-21 Kozminski KG, Johnson KA, Forscher P, Rosenbaum JL: A motility in the eukaryotic flagellum unrelated to flagellar beating. Proc Natl Acad Sci USA 1993;90:5519-5523.

$\checkmark 22$ Scholey JM: Intraflagellar transport. Annu Rev Cell Dev Biol 2003;19:423-443.

-23 Pedersen LB, Rosenbaum JL: Intraflagellar transport (IFT): role in ciliary assembly, resorption and signalling. Curr Top Dev Biol 2008;85:23-61.

-24 Scholey JM: Intraflagellar transport motors in cilia: moving along the cell's antenna. J Cell Biol 2008;180:23-29.
25 Qin H, Diener DR, Geimer S, Cole DG, Rosenbaum JL: Intraflagellar transport (IFT) cargo: IFT transports flagellar precursors to the tip and turnover products to the cell body. J Cell Biol 2004;164:255-266.

26 Blacque OE, Cevik S, Kaplan OI: Intraflagellar transport: from molecular characterisation to mechanism. Front Biosci 2008;13: 2633-2652.

27 Cole DG, Diener DR, Himelblau AL, Beech PL, Fuster JC, Rosenbaum JL: Chlamydomonas kinesin-II-dependent intraflagellar transport (IFT): IFT particles contain proteins required for ciliary assembly in Caenorhabditis elegans sensory neurons. J Cell Biol 1998;141:993-1008.

28 Cole DG: The intraflagellar transport machinery of Chlamydomonas reinhardtii. Traffic 2003;4:1-8.

29 Jekely G, Arendt D: Evolution of intraflagellar transport from coated vesicles and autogenous origin of the eukaryotic cilium. Bioessays 2006;28:191-198.

30 Pazour GJ, Dickert BL, Vucica Y, Seeley ES, Rosenbaum JL, Witman GB, Cole DG: Chlamydomonas IFT88 and its mouse homologue, polycystic kidney disease gene $\operatorname{tg} 737$, are required for assembly of cilia and flagella. J Cell Biol 2000;151:709-718.

31 Tran PV, Haycraft CJ, Besschetnova TY, Turbe-Doan A, Stottmann RW, Herron BJ, Chesebro AL, Qiu H, Scherz PJ, Shah JV, Yoder BK, Beier DR: THM1 negatively modulates mouse sonic hedgehog signal transduction and affects retrograde intraflagellar transport in cilia. Nat Genet 2008;40:403410.

32 Huangfu D, Liu A, Rakeman AS, Murcia NS, Niswander L, Anderson KV: Hedgehog signalling in the mouse requires intraflagellar transport proteins. Nature 2003;426:83-87.

33 Schneider L, Clement CA, Teilmann SC, Pazour GJ, Hoffmann EK, Satir P, Christensen ST: PDGFR $\alpha \alpha$ signaling is regulated through the primary cilium in fibroblasts. Curr Biol 2005; 15:1861-1866.

34 Wang Q, Pan J, Snell WJ: Intraflagellar transport particles participate directly in cilium-generated signaling in Chlamydomonas. Cell 2006;125:549-562.

35 Scholey JM, Anderson KV: Intraflagellar transport and cilium-based signaling. Cell 2006;125:439-442.

36 Lehman JM, Michaud EJ, Schoeb TR, AydinSon Y, Miller M, Yoder BK: The Oak Ridge Polycystic Kidney mouse: Modeling ciliopathies of mice and men. Dev Dyn 2008;237: 1960-1971.

37 Murcia NS, Richards WG, Yoder BK, Mucenski ML, Dunlap JR, Woychik RP: The Oak Ridge Polycystic Kidney (orpk) disease gene is required for left-right axis determination. Development 2000;127:2347-2355.

-38 Barr MM, Sternberg PW: A polycystic kidney-disease gene homologue required for male mating behaviour in C. elegans. Nature 1999;401:386-389.
39 Pazour GJ, San Agustin JT, Follit JA, Rosenbaum JL, Witman GB: Polycystin-2 localizes to kidney cilia and the ciliary level is elevated in orpk mice with polycystic kidney disease. Curr Biol 2002;12:R378-R380.

40 Yoder BK, Hou X, Guay-Woodford LM: The polycystic kidney disease proteins, polycystin-1, polycystin-2, polaris, and cystin, are co-localized in renal cilia. J Am Soc Nephrol 2002;13:2508-2516.

41 Taulman PD, Haycraft CJ, Balkovetz DF, Yoder BK: Polaris, a protein involved in leftright axis patterning, localizes to basal bodies and cilia. Mol Biol Cell 2001;12:589-599.

$\checkmark 42$ Kolb RJ, Nauli SM: Ciliary dysfunction in polycystic kidney disease: an emerging model with polarizing potential. Front Biosci 2008;13:4451-4466.

$\checkmark 43$ Hildebrandt F, Zhou W: Nephronophthisisassociated ciliopathies. J Am Soc Nephrol 2007;18:1855-1871

44 Adams M, Smith UM, Logan CV, Johnson CA: Recent advances in the molecular pathology, cell biology and genetics of ciliopathies. J Med Genet 2008;45:257-267.

45 Salomon R, Saunier S, Niaudet P: Nephronophthisis. Pediatr Nephrol 2008, Epub ahead of print

46 Otto EA, Schermer B, Obara T, O’Toole JF, Hiller KS, Mueller AM, Ruf RG, Hoefele J, Beekmann F, Landau D, Foreman JW, Goodship JA, Strachan T, Kispert A, Wolf MT, et al: Mutations in INVS encoding inversin cause nephronophthisis type 2 , linking renal cystic disease to the function of primary cilia and left-right axis determination. Nat Genet 2003;34:413-420.

47 Sugiyama N, Yokoyama T: Sustained cell proliferation of renal epithelial cells in mice with inv mutation. Genes Cells 2006;11: 1213-1224.

48 Hong DH, Pawlyk B, Sokolov M, Strissel KJ, Yang J, Tulloch B, Wright AF, Arshavsky VY, Li T: RPGR isoforms in photoreceptor connecting cilia and the transitional zone of motile cilia. Invest Ophthalmol Vis Sci 2003;44: 2413-2421.

49 Morgan D, Eley L, Sayer J, Strachan T, Yates LM, Craighead AS, Goodship JA: Expression analyses and interaction with the anaphase promoting complex protein Apc2 suggest a role for inversin in primary cilia and involvement in the cell cycle. Hum Mol Genet 2002; 11:3345-3350.

50 Otto EA, Loeys B, Khanna H, Hellemans J, Sudbrak R, Fan S, Muerb U, O'Toole JF, Helou J, Attanasio M, Utsch B, Sayer JA, Lillo C, Jimeno D, Coucke P, et al: Nephrocystin-5, a ciliary IQ domain protein, is mutated in $\mathrm{Se}$ nior-Loken syndrome and interacts with RPGR and calmodulin. Nat Genet 2005;37: 282-288 
-51 Mollet G, Silbermann F, Delous M, Salomon R, Antignac C, Saunier S: Characterization of the nephrocystin/nephrocystin-4 complex and subcellular localization of nephrocystin- 4 to primary cilia and centrosomes. Hum Mol Genet 2005;14:645-656.

- 52 Winkelbauer ME, Schafer JC, Haycraft CJ, Swoboda P, Yoder BK: The C. elegans homologs of nephrocystin-1 and nephrocystin-4 are cilia transition zone proteins involved in chemosensory perception. J Cell Sci 2005; 118:5575-5587.

-53 Chang B, Khanna H, Hawes N, Jimeno D, He S, Lillo C, Parapuram SK, Cheng H, Scott A, Hurd RE, Sayer JA, Otto EA, Attanasio M, O'Toole JF, Jin G, et al: In-frame deletion in a novel centrosomal/ciliary protein CEP290/ NPHP6 perturbs its interaction with RPGR and results in early-onset retinal degeneration in the rd16 mouse. Hum Mol Genet 2006;15:1847-1857.

-54 Fliegauf M, Horvath J, von Schnakenburg C, Olbrich H, Muller D, Thumfart J, Schermer B, Pazour GJ, Neumann HP, Zentgraf H, Benzing T, Omran H: Nephrocystin specifically localizes to the transition zone of renal and respiratory cilia and photoreceptor connecting cilia. J Am Soc Nephrol 2006;17: 2424-2433.

- 55 Sayer JA, Otto EA, O’Toole JF, Nurnberg G, Kennedy MA, Becker C, Hennies HC, Helou J, Attanasio M, Fausett BV, Utsch B, Khanna H, Liu Y, Drummond I, Kawakami I, et al: The centrosomal protein nephrocystin- 6 is mutated in Joubert syndrome and activates transcription factor ATF4. Nat Genet 2006; 38:674-681

-56 von Schnakenburg C, Fliegauf M, Omran H: Nephrocystin and ciliary defects not only in the kidney? Pediatr Nephrol 2007;22:765769 .

- 57 Delous M, Baala L, Salomon R, Laclef C, Vierkotten J, Tory K, Golzio C, Lacoste T, Besse L, Ozilou C, Moutkine I, Hellman NE, Anselme I, Silbermann F, Vesque C, et al: The ciliary gene RPGRIP1L is mutated in cerebello-oculo-renal syndrome (Joubert syndrome type B) and Meckel syndrome. Nat Genet 2007;39:875-881.

- 58 Ward CJ, Yuan D, Masyuk TV, Wang X, Punyashthiti R, Whelan S, Bacallao R, Torra R, LaRusso NF, Torres VE, Harris PC: Cellular and subcellular localization of the ARPKD protein; fibrocystin is expressed on primary cilia. Hum Mol Genet 2003;12:2703-2710.

-59 Wilson NF, Lefebvre PA: Regulation of flagellar assembly by glycogen synthase kinase 3 in Chlamydomonas reinhardtii. Eukaryot Cell 2004;3:1307-1319.

-60 Qian CN, Knol J, Igarashi P, Lin F, Zylstra U, Teh BT, Williams BO: Cystic renal neoplasia following conditional inactivation of apc in mouse renal tubular epithelium. J Biol Chem 2005;280:3938-3945.
61 Saburi S, Hester I, Fischer E, Pontoglio M, Eremina V, Gessler M, Quaggin SE, Harrison R, Mount R, McNeill H: Loss of Fat 4 disrupts PCP signaling and oriented cell division and leads to cystic kidney disease. Nat Genet 2008;40:1010-1015.

62 Corbit KC, Shyer AE, Dowdle WE, Gaulden J, Singla V, Chen MH, Chuang PT, Reiter JF: Kif3a constrains $\beta$-catenin-dependent Wnt signalling through dual ciliary and non-ciliary mechanisms. Nat Cell Biol 2008;10:7076.

63 Nauli SM, Alenghat FJ, Luo Y, Williams E, Vassilev P, Li X, Elia AE, Lu W, Brown EM, Quinn SJ, Ingber DE, Zhou J: Polycystins 1 and 2 mediate mechanosensation in the primary cilium of kidney cells. Nat Genet 2003; 33:129-137.

64 Schwartz EA, Leonard ML, Bizios R, Bowser SS: Analysis and modeling of the primary cilium bending response to fluid shear. Am J Physiol 1997;272:F132-F138.

65 Praetorius HA, Spring KR: Bending the MDCK cell primary cilium increases intracellular calcium. J Membr Biol 2001;184:7179.

66 Praetorius HA, Spring KR: Removal of the MDCK cell primary cilium abolishes flow sensing. J Membr Biol 2003;191:69-76.

67 Davenport JR, Watts AJ, Roper VC, Croyle MJ, van Groen T, Wyss JM, Nagy TR, Kesterson RA, Yoder BK: Disruption of intraflagellar transport in adult mice leads to obesity and slow-onset cystic kidney disease. Curr Biol 2007; 17:1586-1594.

68 Piontek K, Menezes LF, Garcia-Gonzalez MA, Huso DL, Germino GG: A critical developmental switch defines the kinetics of kidney cyst formation after loss of Pkd1. Nat Med 2007;13:1490-1495.

69 Fischer E, Legue E, Doyen A, Nato F, Nicolas JF, Torres V, Yaniv M, Pontoglio M: Defective planar cell polarity in polycystic kidney disease. Nat Genet 2006;38:21-23.

70 Wu Y, Dai XQ, Li Q, Chen CX, Mai W, Hussain Z, Long W, Montalbetti N, Li G, Glynne R, Wang S, Cantiello HF, Wu G, Chen XZ: Kinesin-2 mediates physical and functional interactions between polycystin-2 and fibrocystin. Hum Mol Genet 2006;15:3280-3292.

71 Wang S, Zhang J, Nauli SM, Li X, Starremans PG, Luo Y, Roberts KA, Zhou J: Fibrocystin/ polyductin, found in the same protein complex with polycystin-2, regulates calcium responses in kidney epithelia. Mol Cell Biol 2007:27:3241-3252.

72 Kim I, Li C, Liang D, Chen XZ, Coffy RJ, Ma J, Zhao P, Wu G: Polycystin-2 expression is regulated by a PC2-binding domain of intracellular portion of fibrocystin. J Biol Chem 2008;283:31559-31566
73 Kim I, Fu Y, Hui K, Moeckel G, Mai W, Li C, Liang D, Zhao P, Ma J, Chen XZ, George AL, Jr, Coffey RJ, Feng ZP, Wu G: Fibrocystin/ polyductin modulates renal tubular formation by regulating polycystin-2 expression and function. J Am Soc Nephrol 2008; 19: 455-468.

-74 Nishio S, Hatano M, Nagata M, Horie S, Koike T, Tokuhisa T, Mochizuki T: Pkd1 regulates immortalized proliferation of renal tubular epithelial cells through p53 induction and JNK activation. J Clin Invest 2005; 115:910-918.

-75 Bhunia AK, Piontek K, Boletta A, Liu L, Qian F, Xu PN, Germino FJ, Germino GG: PKD1 induces p21(waf1) and regulation of the cell cycle via direct activation of the JAK-STAT signaling pathway in a process requiring PKD2. Cell 2002;109:157-168.

76 Low SH, Vasanth S, Larson CH, Mukherjee S, Sharma N, Kinter MT, Kane ME, Obara T, Weimbs T: Polycystin-1, STAT6, and P100 function in a pathway that transduces ciliary mechanosensation and is activated in polycystic kidney disease. Dev Cell 2006;10:5769.

77 Shillingford JM, Murcia NS, Larson CH, Low SH, Hedgepeth R, Brown N, Flask CA, Novick AC, Goldfarb DA, Kramer-Zucker A, Walz G, Piontek KB, Germino GG, Weimbs $\mathrm{T}$ : The mTOR pathway is regulated by polycystin-1, and its inhibition reverses renal cystogenesis in polycystic kidney disease. Proc Natl Acad Sci USA 2006;103:54665471 .

78 Kim E, Arnould T, Sellin LK, Benzing T, Fan MJ, Gruning W, Sokol SY, Drummond I, Walz G: The polycystic kidney disease 1 gene product modulates Wnt signaling. J Biol Chem 1999;274:4947-4953.

-79 Chauvet V, Tian X, Husson H, Grimm DH, Wang T, Hiesberger T, Igarashi $\mathrm{P}$, Bennett AM, Ibraghimov-Beskrovnaya O, Somlo S, Caplan MJ: Mechanical stimuli induce cleavage and nuclear translocation of the polycystin-1 C terminus. J Clin Invest 2004;114: 1433-1443.

80 Weimbs T: Polycystic kidney disease and renal injury repair: common pathways, fluid flow, and the function of polycystin-1. Am J Physiol Renal Physiol 2007;293:F1423F1432.

81 Jauregui AR, Nguyen KC, Hall DH, Barr MM: The Caenorhabditis elegans nephrocystins act as global modifiers of cilium structure. J Cell Biol 2008;180:973-988.

82 Sohara E, Luo Y, Zhang J, Manning DK, Beier DR, Zhou J: Nek8 regulates the expression and localization of polycystin- 1 and polycystin-2. J Am Soc Nephrol 2008;19:469-476.

83 Otto EA, Trapp ML, Schultheiss UT, Helou J, Quarmby LM, Hildebrandt F: NEK8 mutations affect ciliary and centrosomal localization and may cause nephronophthisis. J Am Soc Nephrol 2008;19:587-592. 
84 Bergmann C, Fliegauf M, Bruchle NO, Frank V, Olbrich H, Kirschner J, Schermer B, Schmedding I, Kispert A, Kranzlin B, Nurnberg G, Becker C, Grimm T, Girschick G, Lynch SA, et al: Loss of nephrocystin-3 function can cause embryonic lethality, MeckelGruber-like syndrome, situs inversus, and renal-hepatic-pancreatic dysplasia. Am J Hum Genet 2008;82:959-970.

-85 Simons M, Gloy J, Ganner A, Bullerkotte A, Bashkurov M, Kronig C, Schermer B, Benzing T, Cabello OA, Jenny A, Mlodzik M, Polok B, Driever W, Obara T, Walz G: Inversin, the gene product mutated in nephronophthisis type II, functions as a molecular switch between Wnt signaling pathways. Nat Genet 2005;37:537-543.

86 Nachury MV, Loktev AV, Zhang Q, Westlake CJ, Peranen J, Merdes A, Slusarski DC, Scheller RH, Bazan JF, Sheffield VC, Jackson PK: A core complex of BBS proteins cooperates with the GTPase Rab8 to promote ciliary membrane biogenesis. Cell 2007;129:12011213.

-87 Gerdes JM, Liu Y, Zaghloul NA, Leitch CC, Lawson SS, Kato M, Beachy PA, Beales PL, DeMartino GN, Fisher S, Badano JL, Katsanis N: Disruption of the basal body compromises proteasomal function and perturbs intracellular Wnt response. Nat Genet 2007; 39:1350-1360.

88 Masyuk AI, Masyuk TV, LaRusso NF: Cholangiocyte primary cilia in liver health and disease. Dev Dyn 2008;237:2007-2012.

89 Iomini C, Tejada K, Mo W, Vaananen H, Piperno G: Primary cilia of human endothelial cells disassemble under laminar shear stress. J Cell Biol 2004;164:811-817.

90 Nauli SM, Kawanabe Y, Kaminski JJ, Pearce WJ, Ingber DE, Zhou J: Endothelial cilia are fluid shear sensors that regulate calcium signaling and nitric oxide production through polycystin-1. Circulation 2008;117:11611171.

-91 Hierck BP, Van der Heiden K, Alkemade FE, Van de Pas S, Van Thienen JV, Groenendijk BC, Bax WH, Van der Laarse A, Deruiter MC, Horrevoets AJ, Poelmann RE: Primary cilia sensitize endothelial cells for fluid shear stress. Dev Dyn 2008;237:725-735.

92 Van der Heiden K, Hierck BP, Krams R, de Crom R, Cheng C, Baiker M, Pourquie MJ, Alkemade FE, DeRuiter MC, Gittenbergerde Groot AC, Poelmann RE: Endothelial primary cilia in areas of disturbed flow are at the base of atherosclerosis. Atherosclerosis 2008;196:542-550.

93 Andrae J, Gallini R, Betsholtz C: Role of platelet-derived growth factors in physiology and medicine. Genes Dev 2008;22:12761312.
94 Schneider L, Cammer M, Lehman J, Nielsen SK, Guerra CF, Veland IR, Stock C, Hoffmann EK, Yoder BK, Schwab A, Satir P, Christensen ST: Directional cell migration and chemotaxis in wound healing response to PDGF-AA are coordinated by the primary cilium in fibroblasts, submitted.

95 Schneider L, Stock C, Dieterich P, Jensen BH, Pedersen LB, Satir P, Schwab A, Christensen ST, Pedersen SF: The $\mathrm{Na}^{+} / \mathrm{H}^{+}$exchanger NHE1 plays a central role in directional migration stimulated via PDGFR $\alpha$ in the primary cilium, submitted.

$96 \mathrm{Lu} \mathrm{CJ}, \mathrm{Du} \mathrm{H}, \mathrm{Wu}$ J, Jansen DA, Jordan KL, Xu N, Sieck GC, Qian Q: Non-random distribution and sensory functions of primary cilia in vascular smooth muscle cells. Kidney Blood Press Res 2008;31:171-184.

97 Jensen CG, Poole CA, McGlashan SR, Marko M, Issa ZI, Vujcich KV, Bowser SS: Ultrastructural, tomographic and confocal imaging of the chondrocyte primary cilium in situ. Cell Biol Int 2004;28:101-110.

$\checkmark 98$ McGlashan SR, Jensen CG, Poole CA: Localization of extracellular matrix receptors on the chondrocyte primary cilium. J Histochem Cytochem 2006;54:1005-1014.

$>99$ Kestler HA, Kuhl M: From individual Wnt pathways towards a Wnt signalling network. Philos Trans R Soc Lond B Biol Sci 2008;363:1333-1347.

100 Vlad A, Rohrs S, Klein-Hitpass L, Muller O: The first five years of the Wnt targetome. Cell Signal 2008;20:795-802.

101 Kikuchi A, Yamamoto H: Tumor formation due to abnormalities in the $\beta$-catenin-independent pathway of Wnt signaling. Cancer Sci 2008;99:202-208.

102 Ross AJ, May-Simera H, Eichers ER, Kai M, Hill J, Jagger DJ, Leitch CC, Chapple JP, Munro PM, Fisher S, Tan PL, Phillips HM, Leroux MR, Henderson DJ, Murdoch JN, et al: Disruption of Bardet-Biedl syndrome ciliary proteins perturbs planar cell polarity in vertebrates. Nat Genet 2005;37:11351140.

103 Chan DW, Chan CY, Yam JW, Ching YP, Ng IO: Prickle-1 negatively regulates $\mathrm{Wnt} / \beta$ catenin pathway by promoting Dishevelled ubiquitination/degradation in liver cancer. Gastroenterology 2006;131:1218-1227.

104 Jones C, Roper VC, Foucher I, Qian D, Banizs B, Petit C, Yoder BK, Chen P: Ciliary proteins link basal body polarization to planar cell polarity regulation. Nat Genet 2008;40:69-77.

105 Cano DA, Murcia NS, Pazour GJ, Hebrok M: Orpk mouse model of polycystic kidney disease reveals essential role of primary cilia in pancreatic tissue organization. Development 2004;131:3457-3467.

106 Zhang Q, Davenport JR, Croyle MJ, Haycraft CJ, Yoder BK: Disruption of IFT results in both exocrine and endocrine abnormalities in the pancreas of $\mathrm{Tg} 737$ (orpk) mutant mice. Lab Invest 2005;85:45-64.
107 Willert K, Nusse R: $\beta$-Catenin: a key mediator of Wnt signaling. Curr Opin Genet Dev 1998;8:95-102.

108 Roose J, Clevers H: TCF transcription factors: molecular switches in carcinogenesis. Biochim Biophys Acta 1999;1424:M23M37.

109 Nusse R: WNT targets. Repression and activation. Trends Genet 1999;15:1-3.

110 Varjosalo M, Taipale J: Hedgehog: functions and mechanisms. Genes Dev 2008;22: 2454-2472.

111 Eggenschwiler JT, Anderson KV: Cilia and developmental signaling. Annu Rev Cell Dev Biol 2007;23:345-373.

112 Liu A, Wang B, Niswander LA: Mouse intraflagellar transport proteins regulate both the activator and repressor functions of Gli transcription factors. Development 2005;132:3103-3111.

113 Christensen ST, Ott CM: Cell signaling. A ciliary signaling switch. Science 2007;317: 330-331.

114 Rohatgi R, Milenkovic L, Scott MP: Patched1 regulates hedgehog signaling at the primary cilium. Science 2007;317:372376.

115 Corbit KC, Aanstad P, Singla V, Norman AR, Stainier DY, Reiter JF: Vertebrate Smoothened functions at the primary cilium. Nature 2005;437:1018-1021.

116 Ocbina PJ, Anderson KV: Intraflagellar transport, cilia, and mammalian Hedgehog signaling: analysis in mouse embryonic fibroblasts. Dev Dyn 2008;237:2030-2038.

117 Kovacs JJ, Whalen EJ, Liu R, Xiao K, Kim J, Chen M, Wang J, Chen W, Lefkowitz RJ: $\beta$ Arrestin-mediated localization of smoothened to the primary cilium. Science 2008; 320:1777-1781.

118 Koyama E, Young B, Nagayama M, Shibukawa $Y$, Enomoto-Iwamoto M, Iwamoto $M$, Maeda Y, Lanske B, Song B, Serra R, Pacifici M: Conditional Kif3a ablation causes abnormal hedgehog signaling topography, growth plate dysfunction, and excessive bone and cartilage formation during mouse skeletogenesis. Development 2007;134: 2159-2169.

119 Haycraft CJ, Zhang Q, Song B, Jackson WS, Detloff PJ, Serra R, Yoder BK: Intraflagellar transport is essential for endochondral bone formation. Development 2007;134: 307-316.

120 Cho A, Ko HW, Eggenschwiler JT: FKBP8 cell-autonomously controls neural tube patterning through a Gli2- and Kif3a-dependent mechanism. Dev Biol 2008;321: 27-39.

121 Spassky N, Han YG, Aguilar A, Strehl L, Besse L, Laclef C, Ros MR, Garcia-Verdugo JM, Alvarez-Buylla A: Primary cilia are required for cerebellar development and Shhdependent expansion of progenitor pool. Dev Biol 2008;317:246-259. 
-122 Chizhikov VV, Davenport J, Zhang Q, Shih EK, Cabello OA, Fuchs JL, Yoder BK, Millen KJ: Cilia proteins control cerebellar morphogenesis by promoting expansion of the granule progenitor pool. J Neurosci 2007;27:9780-9789.

123 Vierkotten J, Dildrop R, Peters T, Wang B, Ruther U: Ftm is a novel basal body protein of cilia involved in Shh signalling. Development 2007; 134:2569-2577.

-124 May SR, Ashique AM, Karlen M, Wang B, Shen Y, Zarbalis K, Reiter J, Ericson J, Peterson AS: Loss of the retrograde motor for IFT disrupts localization of Smo to cilia and prevents the expression of both activator and repressor functions of Gli. Dev Biol 2005;287:378-389.

-125 Huangfu D, Anderson KV:Cilia and Hedgehog responsiveness in the mouse. Proc Natl Acad Sci USA 2005; 102:11325-11330.

-126 Caspary T, Larkins CE, Anderson KV: The graded response to Sonic Hedgehog depends on cilia architecture. Dev Cell 2007; 12:767-778.

127 Evangelista M, Lim T, Lee J, Parker L, Ashique A, Peterson A, Ye W, Davis D, de Sauvage F: Kinome siRNA screen identifies regulators of ciliogenesis and hedgehog signal transduction. Sci Signal 2008;1:ra7.

-128 Johnson ET, Nicola T, Roarty K, Yoder BK, Haycraft CJ, Serra R: Role for primary cilia in the regulation of mouse ovarian function. Dev Dyn 2008;237:2053-2060.

-129 Houde C, Dickinson RJ, Houtzager VM, Cullum R, Montpetit R, Metzler M, Simpson EM, Roy S, Hayden MR, Hoodless PA, Nicholson DW: Hippi is essential for node cilia assembly and Sonic hedgehog signaling. Dev Biol 2006;300:523-533.

-130 Kawahira H, Scheel DW, Smith SB, German MS, Hebrok M: Hedgehog signaling regulates expansion of pancreatic epithelial cells. Dev Biol 2005;280:111-121.

$\checkmark 131$ Lau J, Kawahira H, Hebrok M: Hedgehog signaling in pancreas development and disease. Cell Mol Life Sci 2006;63:642-652.
132 Cano DA, Hebrok M, Zenker M: Pancreatic development and disease. Gastroenterology 2007; 132:745-762.

133 van den Brink GR: Hedgehog signaling in development and homeostasis of the gastrointestinal tract. Physiol Rev 2007;87: 1343-1375

134 Nielsen SK, Mollgard K, Clement CA, Veland IR, Awan A, Yoder BK, Novak I, Christensen ST: Characterization of primary cilia and Hedgehog signaling during development of the human pancreas and in human pancreatic duct cancer cell lines. Dev Dyn 2008;237:2039-2052.

135 Cano DA, Sekine S, Hebrok M: Primary cilia deletion in pancreatic epithelial cells results in cyst formation and pancreatitis. Gastroenterology 2006;131:1856-1869.

136 Allan EH, Ho PW, Umezawa A, Hata J, Makishima F, Gillespie MT, Martin TJ: Differentiation potential of a mouse bone marrow stromal cell line. J Cell Biochem 2003; 90:158-169.

137 Hu H, Hilton MJ, Tu X, Yu K, Ornitz DM, Long F: Sequential roles of Hedgehog and Wnt signaling in osteoblast development. Development 2005;132:49-60.

138 Day TF, Yang Y: Wnt and hedgehog signaling pathways in bone development. J Bone Joint Surg Am 2008;90(suppl 1):19-24.

139 Serra R: Role of intraflagellar transport and primary cilia in skeletal development. Anat Rec (Hoboken) 2008;291:1049-1061.

140 Ruiz-Perez VL, Blair HJ, Rodriguez-Andres ME, Blanco MJ, Wilson A, Liu YN, Miles C, Peters H, Goodship JA: Evc is a positive mediator of Ihh-regulated bone growth that localises at the base of chondrocyte cilia. Development 2007; 134:29032912.

141 Nishikawa S, Goldstein RA, Nierras CR: The promise of human induced pluripotent stem cells for research and therapy. Nat Rev Mol Cell Biol 2008;9:725-729.
142 Chumsri S, Burger AM: Cancer stem cell targeted agents: therapeutic approaches and consequences. Curr Opin Mol Ther 2008; 10:323-333.

143 Kiprilov EN, Awan A, Desprat R, Velho M, Clement CA, Byskov AG, Andersen CY, Satir P, Bouhassira EE, Christensen ST, Hirsch RE: Human embryonic stem cells in culture possess primary cilia with hedgehog signaling machinery. J Cell Biol 2008; 180:897-904.

144 Pebay A, Wong RC, Pitson SM, Wolvetang EJ, Peh GS, Filipczyk A, Koh KL, Tellis I, Nguyen LT, Pera MF: Essential roles of sphingosine-1-phosphate and platelet-derived growth factor in the maintenance of human embryonic stem cells. Stem Cells 2005;23:1541-1548.

145 Sato N, Meijer L, Skaltsounis L, Greengard P, Brivanlou AH: Maintenance of pluripotency in human and mouse embryonic stem cells through activation of Wnt signaling by a pharmacological GSK-3-specific inhibitor. Nat Med 2004;10:55-63.

146 Awan A, Olivieri RO, Jensen PL, Christensen ST, Andersen CY: Characterization of human embryonic stem cells (hESCs) grown under feeder-free conditions. Methods Mol Biol 2009, in press.

147 Han YG, Spassky N, Romaguera-Ros M, Garcia-Verdugo JM, Aguilar A, SchneiderMaunoury S, Alvarez-Buylla A: Hedgehog signaling and primary cilia are required for the formation of adult neural stem cells. Nat Neurosci 2008;11:277-284.

148 Komada M, Saitsu H, Kinboshi M, Miura T, Shiota K, Ishibashi M: Hedgehog signaling is involved in development of the neocortex. Development 2008;135:2717-2727.

149 Breunig JJ, Sarkisian MR, Arellano JI, Morozov YM, Ayoub AE, Sojitra S, Wang B, Flavell RA, Rakic P, Town T: Primary cilia regulate hippocampal neurogenesis by mediating sonic hedgehog signaling. Proc Natl Acad Sci USA 2008;105:13127-13132. 